\title{
Influence of Ag Addition on Thermal Stability and Thermophysical Properties of Ti-Zr-Ni Quasicrystals
}

\author{
Sangho Jeon ${ }^{1,2}$, Yong Chan Cho ${ }^{1}$, Yong-Il Kim ${ }^{1,3}$, Yun-Hee Lee ${ }^{1,3}$, Sooheyong Lee ${ }^{1,3}$ and \\ Geun Woo Lee ${ }^{1,3, *}$ \\ 1 Division of Industrial Metrology, Korea Research Institute of Standards and Science, Daejeon 34113, Korea; \\ shjeon8930@gmail.com (S.J.); yccho@kriss.re.kr (Y.C.C.); yikim@kriss.re.kr (Y.-I.K.); \\ uni44@kriss.re.kr (Y.-H.L.); sooheyong@gmail.com (S.L.) \\ 2 Department of Mechanical Engineering, Tufts University, Medford, MA 02155, USA \\ 3 Department of Nano Science, University of Science and Technology, Daejeon 34113, Korea \\ * Correspondence: gwlee@kriss.re.kr; Tel.: +82-042-868-5744
}

Received: 2 May 2020; Accepted: 4 June 2020; Published: 7 June 2020

check for updates

\begin{abstract}
We study the effects of Ag addition on thermal stability and thermophysical properties of Ti-Zr-Ni icosahedral quasicrystals. The Ag addition results in increasing the coherence length and thermal stability of the icosahedral phase (i-phase) of the as-cast $\mathrm{Ti}_{35.2} \mathrm{Zr}_{43.8} \mathrm{Ni}_{21}$ alloy, which are maximized at around 4 at.\% Ag addition. Differential scanning calorimetry (DSC) and electrostatic levitation (ESL) experiments reveal that the addition suppresses the $i$-phase decomposition on heating and cooling. We find that considerable amount of the $i$-phase remains in the samples processed by radiational cooling in ESL as the Ag concentration increases. These results demonstrate that $\mathrm{Ag}$ addition stabilizes the $i$-phase of the $\mathrm{Ti}_{35.2} \mathrm{Zr}_{43.8} \mathrm{Ni}_{21}$ alloy. No anomalous effect of Ag addition is found on density and viscosity of the $\mathrm{Ti}_{35.2} \mathrm{Zr}_{43.8} \mathrm{Ni}_{21}$ liquid.
\end{abstract}

Keywords: Ag addition; icosahedral quasicrystals; thermal stability; thermophysical properties; electrostatic levitation

\section{Introduction}

Small additions of elements onto matrix materials often have a dramatic influence on physical, chemical, and mechanical properties [1,2]. Since understanding such a mechanism is a pivotal issue for fundamental science and applications, a considerable amount of effort has been devoted to studying how small additions alter the physical and chemical properties of materials in the viewpoint of structure [3-5], thermodynamics [6,7], and kinetics [8,9]. For example, small additions of Pd [10-12], $\mathrm{Al}[4]$, and $\mathrm{Nb}[3,13]$ to matrix alloys facilitate the formation of icosahedral short range order (ISRO) or icosahedral medium range order (IMRO) clusters in their liquid, which yields the enhanced glass forming or quasicrystal forming ability of the materials with a larger critical thickness and slower critical cooling rates [14-16]. Since the icosahedral ordering is incompatible with the well-defined long-range periodic order that characterizes crystals, the prevalence of those orderings in liquids can increase the nucleation barrier for crystal formation (i.e., improving glass forming ability (GFA)), but lower it for quasicrystal formation. This is also true even in the case of simple binary $\mathrm{Cu}-\mathrm{Zr}$ alloys. That is, minute compositional change strongly impacts the GFA by changing the number of ISRO or IMRO in the liquid [17-20]. As for another example, Ag addition significantly affects glass forming [21-25] and quasicrystal forming abilities [7,26,27]. Recently, we showed that a small Ag addition to the Ti-Zr-Ni alloy significantly reduces the crystal-liquid interfacial free energy and this is attributed to the formation of IMRO by pairing with $\mathrm{Zr}$ atoms in the liquid, based on electrostatic levitation experiments and ab-initio molecular dynamic (MD) simulation [7]. 
In the present work, we investigate the effects of $\mathrm{Ag}$ addition on the thermal stability and thermophysical properties of Ti-Zr-Ni quasicrystals using electrostatic levitation (ESL), differential scanning calorimetry (DSC), and X-ray diffraction (XRD). A composition of $\mathrm{Ti}_{35.2} \mathrm{Zr}_{43.8} \mathrm{Ni}_{21}$ was selected, which exhibits single $i$-phase in the as-cast condition, and upon cooling and heating, thermal stability and formability of the $i$-phase were investigated as a function of Ag concentration. We here find that Ag addition improves the thermal stability and formation of $\mathrm{Ti}_{35.2} \mathrm{Zr}_{43.8} \mathrm{Ni}_{21}$ quasicrystals. Density and viscosity measurements are carried out to investigate the effect of Ag addition on thermophysical properties of $\mathrm{Ti}_{35.2} \mathrm{Zr}_{43.8} \mathrm{Ni}_{21}$ liquid.

\section{Materials and Methods}

Ti-Zr-Ni-Ag alloys (Ti 99.995\%, Zr 99.95\%, Ni 99.995\%, Ag 99.99\%, Alfa Aesar, Haverhill, MA, USA) were prepared by arc-melting under a high-purity Ar (99.9999\%) atmosphere. A zirconium sphere as an oxygen getter was used to reduce remaining oxygen in the arc-melting chamber prior to melting of the samples. Mass loss of the samples was less than $0.2 \%$ of the initial mass after arc-melting. Structural and thermal characterizations of the alloys were performed by XRD (smartLAB, Rigaku, Tokyo, Japan), using $\mathrm{CuK} \alpha_{1}$ radiation $(\lambda=1.5402 \AA$ ) and DSC (Labsys evo, Setaram, Lyon, France), respectively. For XRD analysis, the instrumental line broadening was evaluated using a standard reference material of lanthanum hexaboride (LaB6, No.: SRM660c produced by NIST, Gaithersburg, MD, USA) and the corresponding instrumental width was subtracted from the width of the XRD peaks. Undercooling and crystallization behaviors of the alloys were studied using the ESL apparatus at the Korea Research Institute of Standards and Science (KRISS) [28]. The samples (approximately $40 \pm 3 \mathrm{mg}$ ) were levitated between two electrodes and melted by two $\mathrm{CO}_{2}$ lasers (a $50 \mathrm{~W}$ laser and a $100 \mathrm{~W}$ laser/Universal) under ultra-high vacuum (UHV) conditions of $\sim 10^{-7}$ Torr. The temperature of samples was monitored with three infrared pyrometers with Si $(0.9 \mu \mathrm{m} / \mathrm{CHINO}$, Tokyo, Japan) and InGaAs $(1.55 \mu \mathrm{m} / \mathrm{CHINO}$ and $1.6 \mu \mathrm{m} /$ Sensortherm, Sulzbach, Germany) detectors. After multiple thermal cycles of samples in the ESL, the mass loss was $1.5 \%$ lower than the initial mass due to evaporation at high temperatures. An ultraviolet (UV) imaging method was used to calculate the volume of levitated samples for density evaluation of the alloy liquids [29,30]. For volume calibration, a tungsten-carbide sphere (a diameter of $2.2 \mathrm{~mm} /$ Industrial Tectonis Inc) was used to obtain a pixel-to-meter conversion factor. Viscosity of the alloy liquids was measured with the oscillation droplet method [20]. For the statistic of experimental results, the XRD and ESL experiments were conducted three to five times at each composition and 2 times for the DSC experiment. Details of the ESL capability and measurement uncertainty are well described in our previous works [28,30,31].

\section{Results and Discussion}

Figure 1 a shows the XRD patterns of as-cast $\left(\mathrm{Ti}_{35.2} \mathrm{Zr}_{43.8} \mathrm{Ni}_{21}\right)_{100-x} \mathrm{Ag}_{x}(0 \leq x \leq 6$ at.\%) alloys. Since the discovery of the as-cast Ti-Zr-Ni quasicrystal [32], single $i$-phase has been found in the wide composition range of $\mathrm{Ti}_{33-45} \mathrm{Zr}_{46-34} \mathrm{Ni}_{21}$, based on XRD and back-scattered scanning electron microscope (SEM) observations [32-34]. Thus, the diffraction peaks of $\mathrm{Ti}_{35.2} \mathrm{Zr}_{43.8} \mathrm{Ni}_{21}$ are indexed by the $i$-phase in Figure $1 \mathrm{a}$ and the calculated quasi-lattice constant is $5.220 \pm 0.005 \AA$. The crystallinity of the $i$-phase increases up to 4 at.\% Ag addition. For the 4.5 at. $\% \mathrm{Ag}$ addition, the $i$-phase is destabilized with broadened peak widths, and C14 Laves phase $(\mathrm{HCP}, \mathrm{a}=5.276 \AA$, $\mathrm{c}=8.645 \AA$, $\mathrm{c} / \mathrm{a}=1.639)$ appears as a minority on the XRD profile. Figure $1 b$ shows the full width at half maximum (FWHM) calculated from the (100000) reflection as a function of Ag concentration. From the FWHM, the coherence length is estimated to be $43.9 \mathrm{~nm}$ at 4.5 at.\% Ag addition, by using the Scherrer's equation [35]. This value is about $67 \%$ larger than that of the $i$-phase with no Ag addition and the effect is slightly better than that of $\mathrm{Pd}$ addition on the $\mathrm{Ti}_{41.5} \mathrm{Zr}_{41.5} \mathrm{Ni}_{17}$ alloy, which increases the coherence length of the $i$-phase by 65\% [11]. 

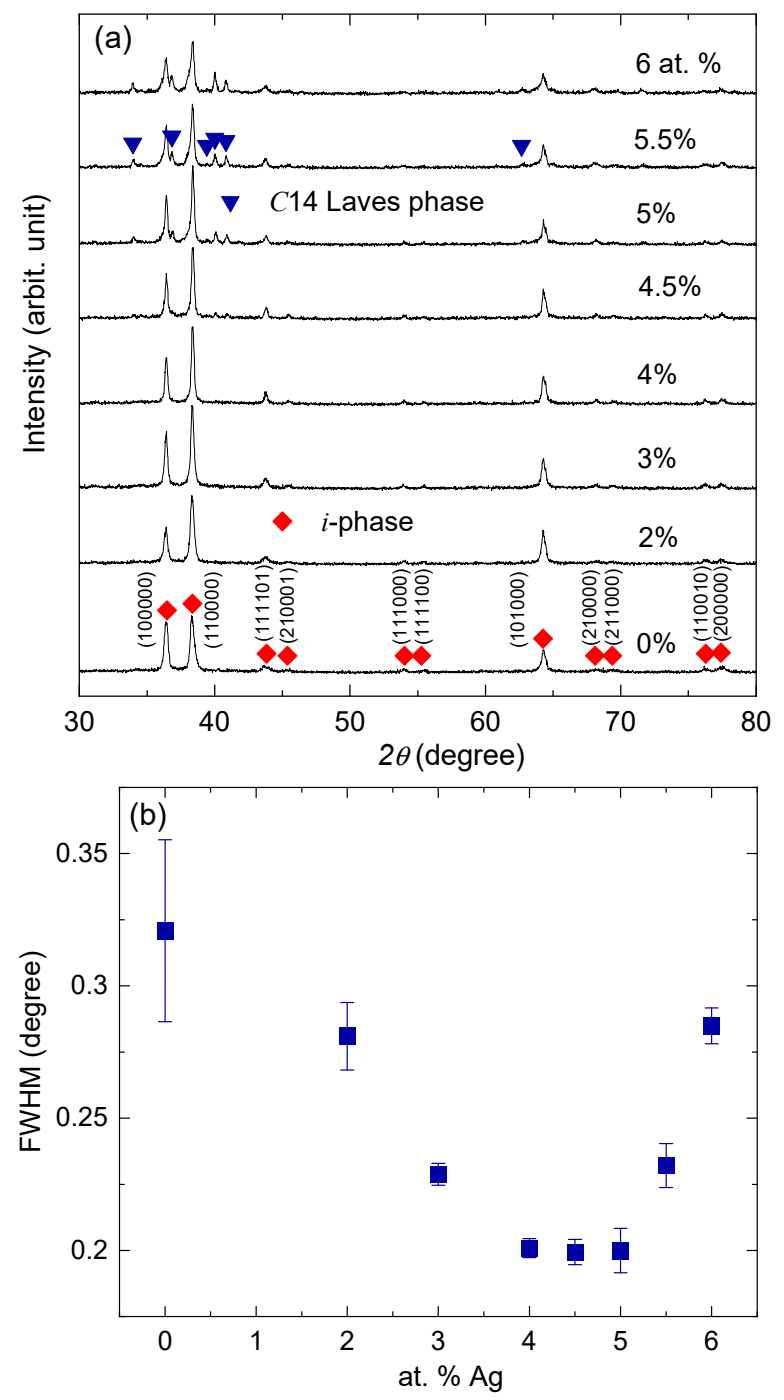

Figure 1. (a) XRD patterns of as-cast $\left(\mathrm{Ti}_{35.2} \mathrm{Zr}_{43.8} \mathrm{Ni}_{21}\right)_{100-x} \mathrm{Ag} x$ alloys. The $i$-phase and $\mathrm{C} 14$ Laves phase were marked by red diamonds $(\bullet)$ and blue triangles $(\mathbf{v})$, respectively. (b) FWHM of the $i$-phase as a function of Ag concentration, which was calculated from the (100000) reflection. Errors indicate the standard deviation.

We investigate the effect of $\mathrm{Ag}$ addition on the thermal stability of the $\mathrm{Ti}_{35.2} \mathrm{Zr}_{43.8} \mathrm{Ni}_{21}$ alloy using DSC. Figure 2 shows the DSC curves of as-cast $\left(\mathrm{Ti}_{35.2} \mathrm{Zr}_{43.8} \mathrm{Ni}_{21}\right)_{100-x} \mathrm{Ag}_{x}$ alloys. All the curves exhibit two endothermic reactions. For the alloy with no Ag addition, the first endothermic event at $936 \mathrm{~K}$ indicates that the $i$-phase transforms into a mixture of the $C 14$ Laves and $\beta(\mathrm{Ti} / \mathrm{Zr}, \mathrm{BCC})$ phases upon heating, which means that the $i$-phase is stable only at low temperatures, as reported in the previous study [36]. The second endothermic event at $1070 \mathrm{~K}$ corresponds to melting $\left(T_{s}\right)$ of the mixture phase of the $C 14$ Laves and $\beta(\mathrm{Ti} / \mathrm{Zr})$ phases, based on the Ti-Zr-Ni phase diagram $[33,34]$. The temperature $\left(T_{x}\right)$ for the $i$-phase decomposition varies significantly with Ag concentration, while minute change for the solidus $\left(T_{s}\right)$ and liquidus $\left(T_{l}\right)$ temperatures is observed. It implies that the Ag addition affects the thermal stability of the crystal phase of $\mathrm{Ti}_{35.2} \mathrm{Zr}_{43.8} \mathrm{Ni}_{21}$, but not that of the liquid phase, significantly. The highest $T_{x}$ is shown at 3 at.\% Ag addition, which differs from the behavior of the FWHM of the $i$-phase in Figure $1 b$. The values of $T_{x}$ are tabulated in Table 1. 


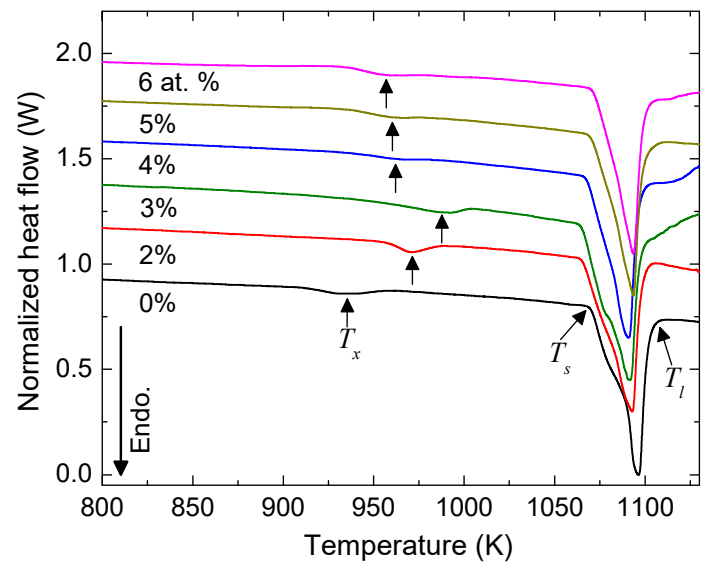

Figure 2. DSC scans of as-cast $\left(\mathrm{Ti}_{35.2} \mathrm{Zr}_{43.8} \mathrm{Ni}_{21}\right)_{100-x} \mathrm{Ag}_{x}$ alloys upon heating with a rate of $10 \mathrm{~K} / \mathrm{min}$. A peak temperature on the first crystallization and solidus and liquidus temperatures were marked by $T_{x}, T_{s}$, and $T_{l}$, respectively.

Table 1. Peak temperatures $\left(T_{x}\right)$ on the first endothermic event. The measurement was conducted 2 times and then the temperature difference is less than $2 \mathrm{~K}$ at each composition.

\begin{tabular}{ccccccc}
\hline at. $\% \mathrm{Ag}$ & 0 & 2 & 3 & 4 & 5 & 6 \\
\hline$T_{x}(\mathrm{~K})$ & 936 & 971 & 992 & 967 & 963 & 960 \\
\hline
\end{tabular}

In order to further investigate the thermal stability of the $i$-phase, we conducted annealing experiments of the as-cast $\left(\mathrm{Ti}_{35.2} \mathrm{Zr}_{43.8} \mathrm{Ni}_{21}\right)_{100-x} \mathrm{Ag}_{x}$ alloys in DSC. All the samples were heated up to $936 \mathrm{~K}$ in the DSC experiment to compare the phase transformation kinetics with Ag concentration. Figure 3 shows XRD patterns of the annealed samples cooled to room temperature. For the sample with no Ag addition, the $i$-phase is completely decomposed into the $C 14$ Laves $(\mathrm{a}=5.231 \AA, \mathrm{c}=8.558 \AA$, $\mathrm{c} / \mathrm{a}=1.636)$ and $\alpha(\mathrm{Ti} / \mathrm{Zr}, \mathrm{HCP})$ solid solution $(\mathrm{a}=3.141 \AA, \mathrm{c}=4.989 \AA, \mathrm{c} / \mathrm{a}=1.588, \mathrm{HCP})$ phases with a small fraction of $(\mathrm{Zr} / \mathrm{Ti})_{2} \mathrm{Ni}$ (tetragonal) phase. However, for the sample with 2 at.\% Ag addition, the $i$-phase remains as a primary phase with a smaller fraction of the $C 14$ Laves phase. A similar behavior is found in the sample with 3 at.\% Ag addition. The sample with 4 at. $\%$ Ag addition exhibits a larger fraction of the $\mathrm{C} 14$ Laves and $\alpha(\mathrm{Ti} / \mathrm{Zr})$ phases and a smaller fraction of the $i$-phase. Accordingly, it could be concluded that small Ag addition enhances the thermal stability of the $i$-phase of as-cast $\left(\mathrm{Ti}_{35.2} \mathrm{Zr}_{43.8} \mathrm{Ni}_{21}\right)_{100-} \mathrm{Ag} x$ alloys up to 3 at.\% $\mathrm{Ag}$ addition.

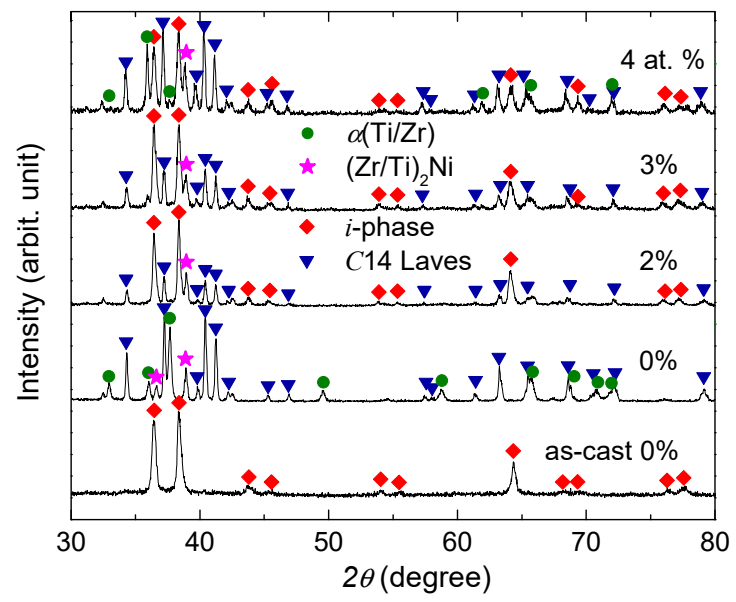

Figure 3. XRD patterns of as-cast $\left(\mathrm{Ti}_{35.2} \mathrm{Zr}_{43.8} \mathrm{Ni}_{21}\right)_{100-x} \mathrm{Ag}_{x}$ alloys cooled after heating up to $936 \mathrm{~K}$ in the DSC experiment, which were measured at room temperature. The $i$-phase, C14 Laves, $\alpha(\mathrm{Ti} / \mathrm{Zr})$, and $(\mathrm{Zr} / \mathrm{Ti})_{2} \mathrm{Ni}$ phases were marked by diamonds $(\bullet)$, triangles $(\mathbf{v})$, circles $(\bullet)$, and stars $(\star)$, respectively. 
It has been reported that the Ti-Zr-Ni $i$-phase to crystalline phase transition is suppressed at high cooling rates in ESL [34]. In order to investigate the effect of Ag addition on the kinetics of the phase transition of $\mathrm{Ti}_{35.2} \mathrm{Zr}_{43.8} \mathrm{Ni}_{21}$ upon cooling in $\mathrm{ESL}$, therefore, we conducted undercooling experiments. Figure 4 a shows the cooling curves of $\left(\mathrm{Ti}_{35.2} \mathrm{Zr}_{43.8} \mathrm{Ni}_{21}\right)_{100-x} \mathrm{Ag}_{x}$ alloy liquids in the ESL. Since heterogeneous nucleation sites are minimized under the containerless condition, the liquids are easily supercooled below their respective liquidus temperatures $T_{l}$, when the heating laser is turned off. At the deeper supercooling, the liquid solidifies to a crystal phase showing a recalescence, i.e., a steep temperature rise by rapid release of latent heat on crystallization, which is identified with the $i$-phase [37]. A following subsequent temperature rise indicates that the $i$-phase decomposes into a mixture of the $C 14$ Laves and $\beta(\mathrm{Ti} / \mathrm{Zr})$ phases, based on previous studies $[33,34,36]$. The $\beta$-phase transforms into $\alpha(\mathrm{Ti} / \mathrm{Zr}$ ) phase during cooling, which corresponds to a slope change of the cooling curve near $800 \mathrm{~K}$ (arrows in Figure 4a) [34,38]. This solidification behavior varies with the addition of Ag. The step recalescence and the slope change become weaker as the Ag concentration increases, and above 4 at.\% Ag addition, we observe a single recalescence event. In addition, during the post-recalescence the plateau temperature decreases as the $\mathrm{Ag}$ concentration increases and is minimized at 4 at.\% $\mathrm{Ag}$ addition. Note that the recalescence occurs in the temperature range of the $C 14$ Laves and $\beta$-phases, as shown in the DSC scans (Figure 2). In other words, the $i$-phase formed from the liquid is metastable in this temperature range. Accordingly, these behaviors imply that the Ag addition facilitates the formation of the metastable $i$-phase and also suppresses the formation of the mixture phase on cooling.

The improved formability of the $i$-phase is confirmed with XRD measurements of the samples processed in the ESL, as shown in Figure $4 \mathrm{~b}$; while no $i$-phase remains in the sample with no Ag addition, the sample with 4.5 at.\% Ag addition still contains $i$-phase that is about $20 \%$ of the volume fraction. More than this concentration, the volume fraction of $i$-phase decreases again in the samples. Note that the correlation between the stability of the $i$-phase and Ag concentration is slightly different on cooling (Figure 4) and heating (Figures 2 and 3). This may be due to a different kinetic effect on the phase transformation or a different cooling-rate dependence on the thermal stability of the $i$-phase, C14 Laves, and $\beta$-phases in $\mathrm{Ti}_{35.2} \mathrm{Zr}_{43.8} \mathrm{Ni}_{21}$. We reported that upon solidification of the $\mathrm{Ti}_{37} \mathrm{Zr}_{42} \mathrm{Ni}_{21}$ liquid, the cooling rate to suppress the $i$-phase to crystalline phase transformation should be higher than $100 \mathrm{~K} / \mathrm{s}$ [34]. The $i$-phase of Ti-Zr-Ni alloys could not survive by radiational cooling in ESL [33,34,37]. In this ESL experiment, the presented cooling rate is approximately $10 \mathrm{~K} / \mathrm{s}$, as shown in Figure 4a, and thus this demonstrates that the Ag addition effectively stabilizes the $i$-phase upon solidification of $\mathrm{Ti}_{35.2} \mathrm{Zr}_{43.8} \mathrm{Ni}_{21}$ liquid.

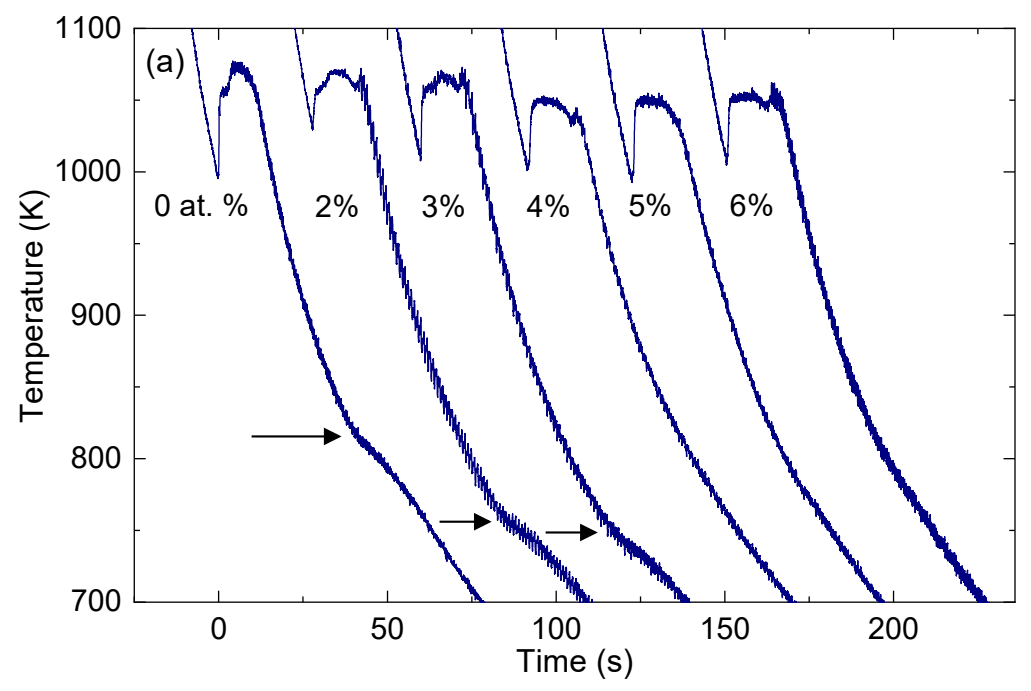

Figure 4. Cont. 


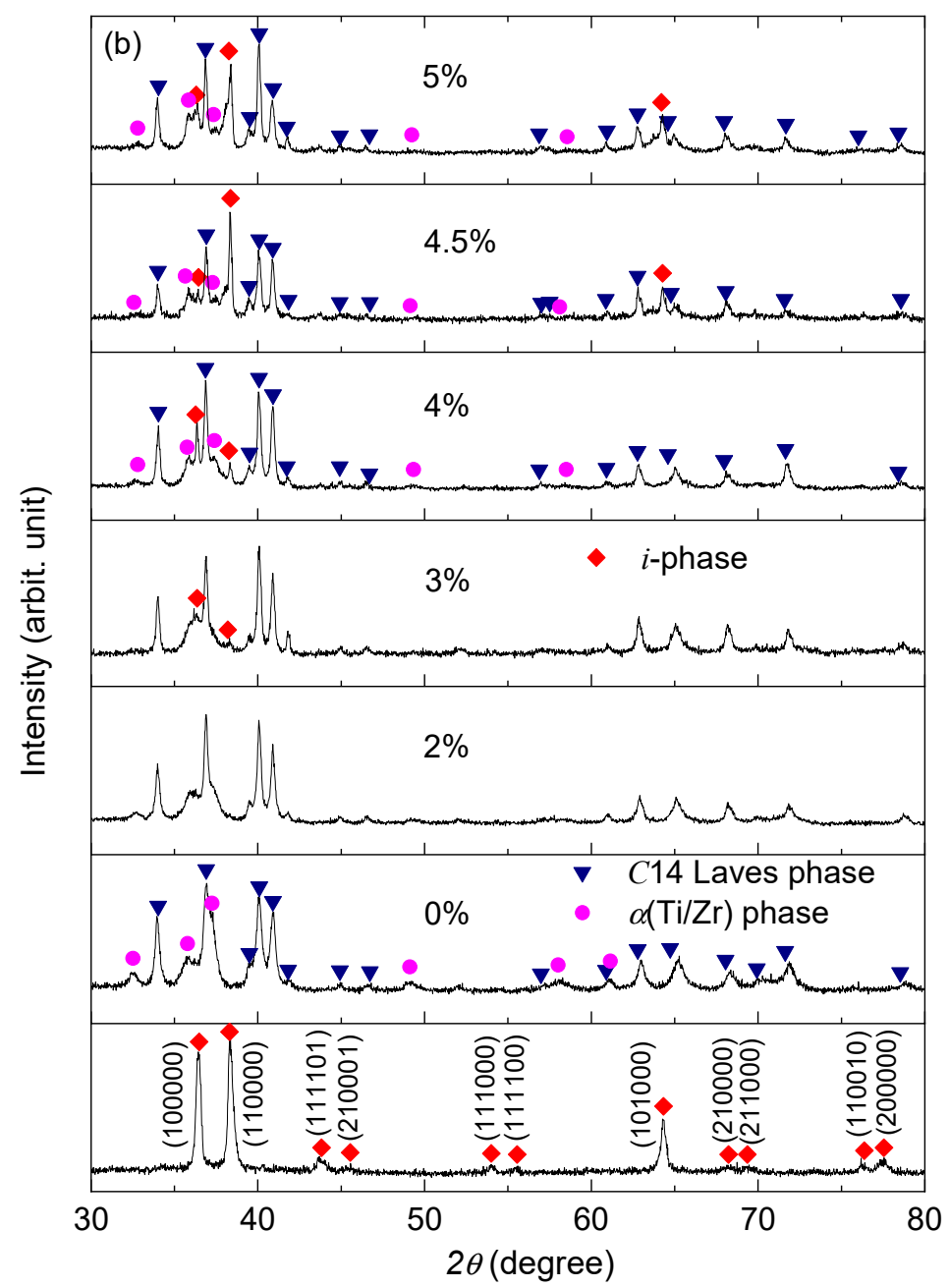

Figure 4. (a) Temperature-time profiles of $\left(\mathrm{Ti}_{35.2} \mathrm{Zr}_{43.8} \mathrm{Ni}_{21}\right)_{100-x} \mathrm{Ag} x$ alloy liquids in the ESL experiment. (b) XRD patterns of $\left(\mathrm{Ti}_{35.2} \mathrm{Zr}_{43.8} \mathrm{Ni}_{21}\right)_{100-x} \mathrm{Ag}_{x}$ alloys processed by ESL. The $i$-phase, C14 Laves, and $\alpha(\mathrm{Ti} / \mathrm{Zr})$ phases were marked by diamonds $(\bullet)$, triangles $(\mathbf{v})$, and circles $(\bullet)$, respectively.

We further investigate the effect of $\mathrm{Ag}$ addition from thermophysical properties of $\mathrm{Ti}_{35.2} \mathrm{Zr}_{43.8} \mathrm{Ni}_{21}$ liquid. Figure 5 shows the viscosity, density, and thermal expansion coefficient of $\left(\mathrm{Ti}_{35.2} \mathrm{Zr}_{43.8} \mathrm{Ni}_{21}\right)_{100-x} \mathrm{Ag}_{x}$ alloy liquids. The thermal expansion coefficient $\alpha_{\mathrm{T}}\left(=V^{-1} d V / d T, V=\right.$ sample volume) was calculated from the measured volume-temperature data. The result of the viscosity measurement shows no significant dependence of $\mathrm{Ag}$ concentration in the stable and supercooled regions and the results are similar with that of a $\mathrm{Ti}_{39.5} \mathrm{Zr}_{39.5} \mathrm{Ni}_{21}$ liquid [39] (Figure 5a). The density increases linearly with $\mathrm{Ag}$ concentration at their respective $T_{l}$ due to the higher density of $\mathrm{Ag}$ than that of the matrix material [40]. The thermal expansion coefficient also increases linearly as a function of Ag concentration (Figure 5b). A similar behavior was also found in $\mathrm{Zr}-\mathrm{Hf}$ and $\mathrm{Zr}$-Ti alloy liquids [41]; both the density and thermal expansion exhibit a linear or a non-linear change with the concentration of $\mathrm{Hf}$ or Ti. This implies that the interatomic interactions in the $\mathrm{Ti}_{35.2} \mathrm{Zr}_{43.8} \mathrm{Ni}_{21}$ liquid vary linearly with Ag concentration and affect both the density and thermal expansion in terms of extended ISRO or IMRO, as expected in our previous work [7]. This evaluation requires further studies in a wider composition range of Ag concentration. 

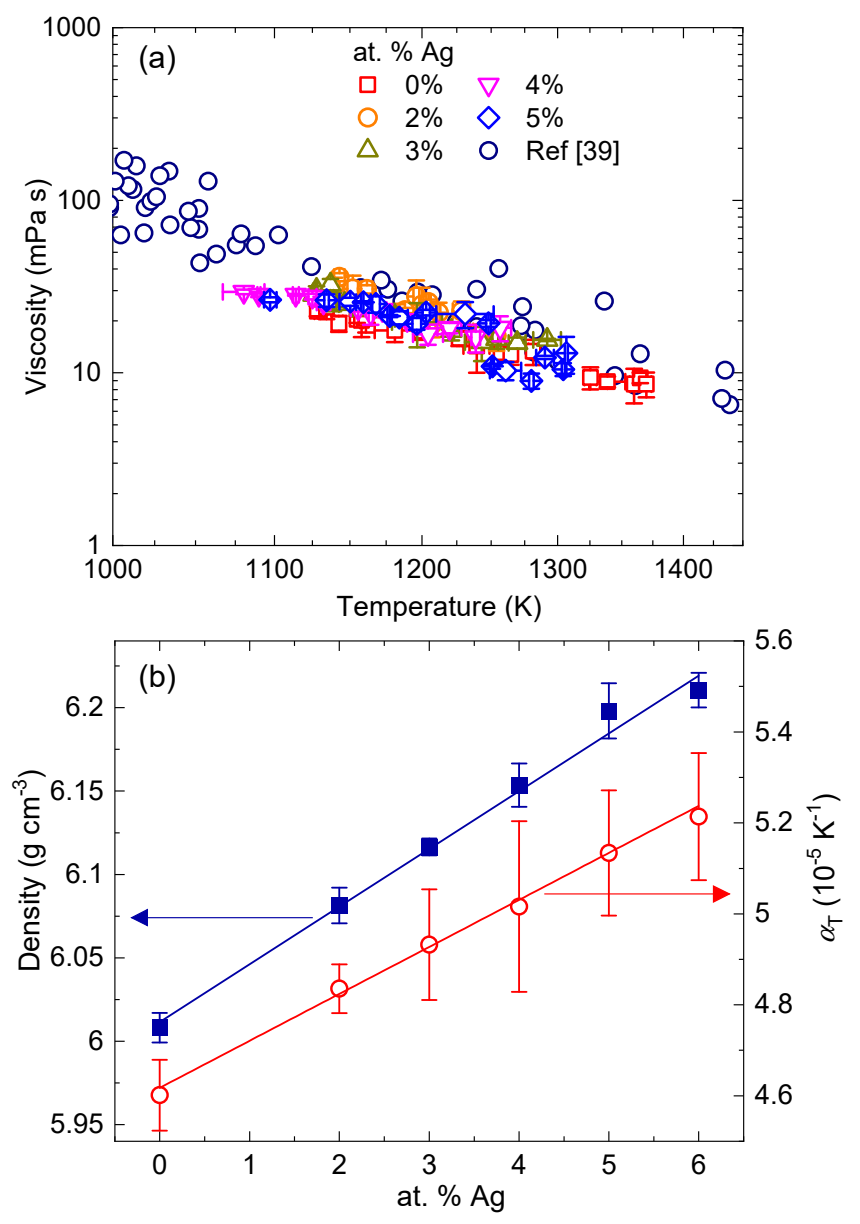

Figure 5. (a) Viscosity of $\left(\mathrm{Ti}_{35.2} \mathrm{Zr}_{43.8} \mathrm{Ni}_{21}\right)_{100-x} \mathrm{Ag} x$ alloy liquids as a function of temperature. (b) Density (left) and thermal expansion coefficient $\alpha_{\mathrm{T}}$ (right) of $\left(\mathrm{Ti}_{35.2} \mathrm{Zr}_{43.8} \mathrm{Ni}_{21}\right)_{100-x} \mathrm{Ag}_{x}$ alloy liquids as a function of Ag concentration at their respective $T_{l}$.

\section{Conclusions}

In summary, we have studied the effect of $\mathrm{Ag}$ addition on the formation and thermal stability of $\mathrm{Ti}_{35.2} \mathrm{Zr}_{43.8} \mathrm{Ni}_{21}$ icosahedral quasicrystals using DSC, XRD, and ESL. The small Ag addition increases the coherence length and thermal stability of the $i$-phase upon heating and suppresses the $i$-phase decomposition on cooling. We find that the $i$-phase remains in the ESL-processed samples on radiational cooling, as the Ag concentration increases, indicating the effective stabilization of the $i$-phase of the $\mathrm{Ti}_{35.2} \mathrm{Zr}_{43.8} \mathrm{Ni}_{21}$ alloy with Ag addition. The density and thermal expansion coefficient of $\mathrm{Ti}_{35.2} \mathrm{Zr}_{43.8} \mathrm{Ni}_{21}$ liquid increases as a function of Ag concentration, but no significant change in the liquid viscosity. The present results show that the addition of Ag indeed carries significant effect on the stability of the $\mathrm{Ti}_{35.2} \mathrm{Zr}_{43.8} \mathrm{Ni}_{21}$ quasicrystals.

Author Contributions: Conceptualization, G.W.L.; Sample preparation, ESL and DSC study, S.J.; Viscosity and density measurements, Y.C.C., Y.-H.L. and S.L.; XRD measurement, Y.-I.K. and Y.C.C; Analysis and Discussion, all authors; Writing — original draft preparation, S.J.; Writing — draft review and editing, all authors.; Supervision, G.W.L. All authors have read and agreed to the published version of the manuscript.

Funding: This research was supported by the Converging Research Center Program through the Ministry of Science, ICT and Future Planning, Korea (Grants No. NRF-2014M3C1A8048818 and No. NRF-2014M1A7A1A01030128), and the Korea Research Institute of Standards and Science (KRISS-2017-GP2017-0029).

Conflicts of Interest: The authors declare no conflict of interest. 


\section{References}

1. Wang, W.H. Roles of minor additions in formation and properties of bulk metallic glasses. Prog. Mater. Sci. 2007, 52, 540-596. [CrossRef]

2. Lu, Z.P.; Liu, C.T. Role of minor alloying additions in formation of bulk metallic glasses: A review. J. Mater. Sci. 2004, 39, 3965-3974. [CrossRef]

3. Wu, S.Y.; Wei, S.H.; Guo, G.O.; Wang, J.G.; Yang, L. Structural mechanism of the enhanced glass-forming ability in multicomponent alloys with positive heat of mixing. Sci. Rep. 2016, 6, 38098. [CrossRef] [PubMed]

4. Li, F.; Zhang, H.; Liu, X.; Dong, Y.; Yu, C.; Lu, Z. Effects of Al addition on atomic structure of Cu-Zr metallic glass. J. Appl. Phys. 2018, 123, 055101. [CrossRef]

5. Kim, H.K.; Lee, M.; Lee, K.-R.; Lee, J.-C. How can a minor element added to a binary amorphous alloy simultaneously improve the plasticity and glass-forming ability? Acta Mater. 2013, 61, 6597-6608. [CrossRef]

6. Wang, Q.; Liu, C.T.; Yang, Y.; Liu, J.B.; Dong, Y.D.; Lu, J. The atomic-scale mechanism for the enhanced glass-forming-ability of a Cu-Zr based bulk metallic glass with minor element additions. Sci. Rep. 2014, 4, 4648. [CrossRef]

7. Lee, G.W.; Cho, Y.C.; Lee, B.; Kelton, K.F. Interfacial free energy and medium range order: Proof of an inverse of Frank's hypothesis. Phys. Rev. B 2017, 95, 054202. [CrossRef]

8. Chathoth, S.M.; Damaschke, B.; Embs, J.P.; Samwer, K. Giant changes in atomic dynamics on microalloying metallic melt. Appl. Phys. Lett. 2009, 95, 191907. [CrossRef]

9. Chen, C.J.; Podlesnyak, A.; Mamontov, E.; Wang, W.H.; Chathoth, S.M. Microscopic insight into the origin of enhanced glass-forming ability of metallic melts on micro-alloying. Appl. Phys. Lett. 2015, 107, 131901. [CrossRef]

10. Saksl, K.; Franz, H.; Jóvári, P.; Klementiev, K.; Welter, E.; Ehnes, A.; Saida, J.; Inoue, A.; Jiang, J.Z. Evidence of icosahedral short-range order in $\mathrm{Zr}_{70} \mathrm{Cu}_{30}$ and $\mathrm{Zr}_{70} \mathrm{Cu}_{29} \mathrm{Pd}_{1}$ and metallic glasses. Appl. Phys. Lett. 2003, 83, 3924-3926. [CrossRef]

11. Davis, J.P.; Majzoub, E.H.; Simmons, J.M.; Kelton, K.F. Ternary phase diagram studies in Ti-Zr-Ni alloys. Mater. Sci. Eng. 2000, 294, 104-107. [CrossRef]

12. Hua, N.; Chen, W. Enhancement of glass-forming ability and mechanical property of Zr-based Zr-Al-Ni bulk metallic glasses with addition of Pd. J. Alloy Compd. 2017, 693, 816-824. [CrossRef]

13. Zhu, Z.; Zhang, W.; Xie, G.; Inoue, A. Relation between glass and quasicrystal formation in the $\mathrm{Zr}-\mathrm{Nb}-\mathrm{Cu}-\mathrm{Ni}-\mathrm{Al}$ alloys upon solidification. Appl. Phys. Lett. 2010, 97, 031919. [CrossRef]

14. Xu, D.; Duan, G.; Johnson, W.L. Unusual Glass-Forming Ability of Bulk Amorphous Alloys Based on Ordinary Metal Copper. Phys. Rev. Lett. 2004, 92, 245504. [CrossRef] [PubMed]

15. Lou, H.B.; Wang, X.D.; Xu, F.; Ding, S.Q.; Cao, Q.P.; Hono, K.; Jiang, J.Z. 73 mm-diameter bulk metallic glass rod by copper mould casting. Appl. Phys. Lett. 2011, 99, 051910. [CrossRef]

16. Wang, D.; Tan, H.; Li, Y. Multiple maxima of GFA in three adjacent eutectics in $\mathrm{Zr}-\mathrm{Cu}-\mathrm{Al}$ alloy system-A metallographic way to pinpoint the best glass forming alloys. Acta Mater. 2005, 53, 2969-2979. [CrossRef]

17. Kang, D.-H.; Zhang, H.; Yoo, H.; Lee, H.H.; Lee, S.; Lee, G.W.; Lou, H.; Wang, X.; Cao, Q.; Zhang, D.; et al. Interfacial free energy controlling glass-forming ability of Cu-Zr alloys. Sci. Rep. 2014, 4, 5167. [CrossRef]

18. Yang, L.; Guo, G.Q.; Chen, L.Y.; Huang, C.L.; Ge, T.; Chen, D.; Liaw, P.K.; Saksl, K.; Ren, Y.; Zeng, Q.S.; et al. Atomic-scale mechanisms of the glass-forming ability in metallic glasses. Phys. Rev. Lett. 2012, 109, 105502. [CrossRef]

19. Bendert, J.C.; Gangopadhyay, A.K.; Mauro, N.A.; Kelton, K.F. Volume expansion measurements in metallic liquids and their relation to fragility: An energy landscape interpretation. Phys. Rev. Lett. 2012, 109, 185901. [CrossRef]

20. Ganorkar, S.; Lee, S.; Lee, Y.-H.; Ishikawa, T.; Lee, G.W. Origin of glass forming ability of Cu-Zr alloys: A link between compositional variation and stability of liquid and glass. Phys. Rev. Mater. 2018, 2, 115606. [CrossRef]

21. Park, E.S.; Kang, H.G.; Kim, W.T.; Kim, D.H. The effect of Ag addition on the glass-forming ability of $\mathrm{Mg}-\mathrm{Cu}-\mathrm{Y}$ metallic glass alloys. J. Non-Cryst. Solids 2011, 279, 154-160. [CrossRef]

22. Fujita, T.; Konno, K.; Zhang, W.; Kumar, V.; Matsuura, M.; Inoue, A.; Sakurai, T.; Chen, M.W. Atomic-scale heterogeneity of a multicomponent bulk metallic. Phys. Rev. Lett. 2009, 103, 075502. [CrossRef] [PubMed] 
23. Zhang, W.; Jia, F.; Zhang, Q.; Inoue, A. Effects of additional Ag on the thermal stability and glass-forming ability of $\mathrm{Cu}-\mathrm{Zr}$ binary glassy alloys. Mater. Sci. Eng. 2007, 459, 330-336. [CrossRef]

24. Gammer, C.; Escher, B.; Ebner, C.; Minor, A.M.; Karnthaler, H.P.; Eckert, J.; Pauly, S.; Rentenberger, C. Influence of the Ag concentration on the medium-range order in a CuZrAlAg bulk metallic glass. Sci. Rep. 2017, 7, 44903. [CrossRef] [PubMed]

25. Nicula, R.; Ponkratz, U.; Jianu, A.; Schick, C.; Burkel, E. Icosahedral phase formation in Ag-substituted Ti-Zr-Ni rapidly-quenched alloys. Mater. Sci. Eng. 2000, 294, 90-92. [CrossRef]

26. Lee, G.W.; Gangopadhyay, A.K.; Kelton, K.F. Effect of microalloying on the formation and stability of the Ti-Zr-Ni icosahedral quasicrystal. J. Alloy Compd. 2012, 537, 171-174. [CrossRef]

27. Zhou, W.; Lin, X.; Li, J.F. Effects of Ag addition on crystallization, microstructure and mechanical properties of $\mathrm{Zr}-\mathrm{Cu}-\mathrm{Ni}-\mathrm{Al}-\mathrm{Ag}$ bulk metallic glasses. J. Alloy Compd. 2013, 552, 102-106. [CrossRef]

28. Lee, G.W.; Jeon, S.; Kang, D.-H. Crystal-liquid interfacial free energy of supercooled liquid Fe using a containerless technique. Cryst. Growth Des. 2013, 13, 1786-1792. [CrossRef]

29. Ishikawa, T.; Paradis, P.-F.; Yoda, S. New sample levitation initiation and imaging techniques for the processing of refractory metals with an electrostatic levitator furnace. Rev. Sci. Instrum. 2001, 72, 2490-2495. [CrossRef]

30. Yoo, H.; Park, C.; Jeon, S.; Lee, S.; Lee, G.W. Uncertainty evaluation for density measurements of molten Ni, $\mathrm{Zr}, \mathrm{Nb}$ and $\mathrm{Hf}$ by using a containerless method. Metrologia 2015, 52, 677-684. [CrossRef]

31. Lee, G.W.; Jeon, S.; Park, C.; Kang, D.-H. Crystal-liquid interfacial free energy and thermophysical properties of pure liquid Ti using electrostatic levitation: Hypercooling limit, specific heat, total hemispherical emissivity, density, and interfacial free energy. J. Chem. Thermodyn. 2013, 63, 1-6. [CrossRef]

32. Lee, G.W.; Croat, T.K.; Gangopadhyay, A.K.; Kelton, K.F. Icosahedral-phase formation in as-cast Ti-Zr-Ni alloys. Philos. Mag. Lett. 2002, 82, 199-205. [CrossRef]

33. Lee, G.W.; Gangopadhyay, A.K.; Croat, T.K.; Rathz, T.J.; Hyers, R.W.; Rogers, J.R.; K. F.; Kelton, K.F. Link between liquid structure and the nucleation barrier for icosahedral quasicrystal, polytetrahedral, and simple crystalline phases in Ti-Zr-Ni alloys: Verification of Frank's hypothesis. Phys. Rev. B 2005, 72, 174107. [CrossRef]

34. Lee, G.W.; Gangopadhyay, A.K.; Kelton, K.F. Phase diagram studies of Ti-Zr-Ni alloys containing less than 40 at.\% $\mathrm{Ni}$ and estimated critical cooling rate for icosahedral quasicrystal formation from the liquid. Acta Mater. 2011, 12, 4964-4973. [CrossRef]

35. Warren, B.E. X-ray diffraction methods. J. Appl. Phys. 1941, 12, 375-383. [CrossRef]

36. Park, G.H.; Hong, S.H.; Kim, J.T.; Park, H.J.; Seo, Y.; Suh, J.Y.; Hong, S.; Park, J.M.; Kim, K.B. Phase transformation and mechanical properties of as-cast $\mathrm{Ti}_{41.5} \mathrm{Zr}_{41.5} \mathrm{Ni}_{17}$ quasicrystalline composites. J. Non-Cryst. Solids 2014, 392, 6-10. [CrossRef]

37. Kelton, K.F.; Lee, G.W.; Gangophdhyay, A.K.; Hyers, R.W.; Rathz, T.J.; Rogers, J.R.; Robinson, M.B.; Robinson, D.S. First X-ray scattering studies on electrostatically levitated metallic liquids: Demonstrated influence of local icosahedral order on the nucleation barrier. Phys. Rev. Lett. 2003, 90, 195504. [CrossRef]

38. Arroyave, R.; Eagar, T.W.; Kaufman, L. Thermodynamic assessment of the Cu-Ti-Zr system. J. Alloy Compd. 2003, 351, 158-170. [CrossRef]

39. Hyers, R.W.; Bradshaw, R.C.; Rogers, J.R.; Rathz, T.J.; Lee, G.W.; Gangopadhyay, A.K.; Kelton, K.F. Surface tension and viscosity of quasicrystal-forming Ti-Zr-Ni Alloys. Int. J. Thermophys. 2004, 25, 1155-1162. [CrossRef]

40. Cho, Y.C.; Kim, B.S.; Yoo, H.; Kim, J.Y.; Lee, S.; Lee, Y.-H.; Lee, G.W.; Jeong, S.Y. Successful melting and density measurements of $\mathrm{Cu}$ and $\mathrm{Ag}$ single crystals with an electrostatic levitation (ESL) system. CrystEngComm 2014, 16, 7575-7579. [CrossRef]

41. Jeon, S.; Kang, D.-H.; Lee, Y.H.; Lee, S.; Lee, G.W. Effect of atomic size on undercoolability of binary solid solution alloy liquids with $\mathrm{Zr}, \mathrm{Ti}$, and Hf using electrostatic levitation. J. Chem. Phys. 2016, 145, 174504. [CrossRef] [PubMed]

(C) 2020 by the authors. Licensee MDPI, Basel, Switzerland. This article is an open access article distributed under the terms and conditions of the Creative Commons Attribution (CC BY) license (http://creativecommons.org/licenses/by/4.0/). 